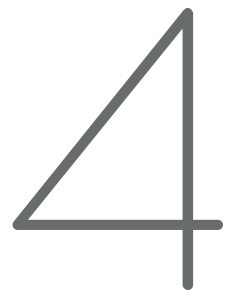

\title{
DISEÑO Y DEPENDENCIA
}

\author{
Arq. Dora Giordano
}


Mucho se ha hablado y escrito sobre el tema de la dependencia en nuestros países, desde el panfleto político, hasta los análisis más profundos y esclarecedores sobre la realidad latinoamericana.

En todos los casos el diagnóstico señala causas y efectos de la hegemonía ejercida por los países centrales y nuestra condición de dependencia, como países periféricos.

La concientización obviamente necesaria, sobre esta problemática, nos lleva a reflexionar sobre una conclusión común: la liberación no vendrá por benevolencia o paternalismo de otros, sino por nuestras convicciones, comprometidas y asumidas en la participación.

Nuestra situación de dependencia inhibe la potencialidad de una fuerza heredada para hacer caminos propios. Pasado y presente de nuestra América testimonian una vocación común de no dependencia, desde los planteos revolucionarios hasta marchas y contramarchas por caminos menos cruentos.

El objetivo de nuestro análisis es buscar respuestas a los interrogantes que surgen de la denuncia o la polémica, sobre la problemática de dependencia, para que ésta no quede separada, de nuestro campo de acción: el diseño.

\section{Realidad y utopía}

El hábitat social que define nuestro contexto, se rige por una lógica a la que están subordinadas las relaciones y elementos del sistema.

La realidad está condicionada entonces, por un sistema que se autorregula y evoluciona según sus objetivos.

En una lógica determinada no caben las utopías, porque son elementos que no tienen lugar en la realidad de ese sistema. El poder central prefigura ideológicamente esa realidad. De este modo, las 
conductas y necesidades de una sociedad dependiente, son condicionadas por respuestas preestablecidas. Lo demás sería utópico para ese esquema de realidad.

Ahora bien, si relativizáramos los conceptos puestos en juego, podríamos definir utopía en términos menos rígidos: de un elemento que no tiene lugar en la realidad, pasaríamos a un elemento que-pre figura la posibilidad de transformar lo real. Planteado el tema de esta manera, sería factible incorporar utopías al sistema para señalar otras alternativas de realidad.

La calibración sucesiva de una transformación estaría entonces, en la presencia permanente en nuestro hábitat de elementos utópicos para el sistema imperante.

El diseño en su área de acción puede ser generador en esa transformación deseable. Si por el contrario, se adecuara a las pautas del sistema, su inserción sería limitada y consecuente con esa realidad.

\section{Desarrollo y subdesarrollo}

Hablar de dependencia implica necesariamente, un reconocimiento del poder dominante, desde la complacencia interesada, hasta la resignación fatalista. Esto se explica cuando la realidad se mide en esa sola dimensión, según una escala o gradiente de progreso en el sentido específico de desarrollo comparativo.

La escala desarrollo-subdesarrollo no es dialéctica, puesto que tal concepto define una síntesis comprensiva y valorativa entre los extremos.

Cuando un extremo se justifica y se asume por la existencia del otro, estaríamos en la interpretación de Hegel, sobre la dialéctica del amo y el esclavo.

Sabemos que la realidad es multifacética. Si la recortamos según este esquema de desarrollo, aparecen dos referentes de la cultura material: el que posibilita lo más y el que determina lo menos. Las condiciones políticas y económicas de América Latina, nos ubican en posición relegada, aún en los casos de relativo avance tecnológico. 
Los intentos de competencia en ese plano de operación, se manifiestan en falsas ostentaciones de industria local o en "desarrollos reflejos", según palabras de Eduardo Galeano. Este parece ser para nosotros, el punto crucial de deslinde. Deberíamos llegar a un planteo posible orientado en otra dirección.

Nuestra problemática de diseño tendría que ser abordada definiendo claramente la base ideológica.

Realidad y utopía o desarrollo-sub-desarrollo constituyen dos ejes semánticos diferenciados y el compromiso es ineludible para el diseñador.

\section{Un modelo ficticio}

El poder comunicacional representa en nuestro medio, la forma más clara de dominación. Controla, induce y condiciona las conductas hasta absorber incluso, la capacidad de crítica del receptor.

Si analizáramos conscientemente nuestra realidad en términos de hábitat material, podríamos caracterizar el "modelo" vigente. El medio construido y los objetos de uso nos dan el indicio más elocuente.

La definición de modelo implica una representación posible de realidad. Para estructurar un modelo es necesaria una interpretación o determinada visión de lo que se va a representar. Así se definen las pautas y códigos hasta llegar a abarcar escala de valores, paradigmas y procesos evolutivos en el modelo.

La sociedad va internalizando lentamente esas pautas y códigos, con aparente y asombrosa naturalidad.

Aún así, si profundizáramos el análisis, encontraríamos síntomas de sobrevivencia de otro modelo que perdura como raíz cultural.

La idiosincrasia popular, mezcla, valora y superpone significados propios que manifiestan una contradicción en el modelo. En su libro "Los laberintos de la crisis" dice Alcira Argumedo (Socióloga): "Pueden 
detectarse signos, comportamientos, códigos que indicarían que la aparente pasividad no es consenso o alienación. Las diversas manifestaciones de la cultura, la vida cotidiana, tienen claro sentido de resistencia y aún de burla hacia lo dominante, que se expresan a través de distintos medios".

Lo que tratamos de rescatar es esa contracara de la realidad, evocando y revalorizando otras pautas, otros códigos, otras imágenes.

Cuando un modelo se instaura y confirma socialmente pierde su condición de artificio cultural y se manifiesta en aparente naturalidad.

Por el contrario un modelo genuino, caracterizado por nuestros rasgos, convertiría el artificio en identidad, un concepto culturalmente válido.

La superposición creciente de signos y señales de un modelo alternativo sobre el actual, generaría en la comunicación una primera fase de complejidad positiva.

\section{Pasado y presente}

Esta intención reivindicadora de nuestra cultura no puede ni debe quedarse en una valoración retrospectiva y gozosa de un patrimonio del pasado.

De ningún modo la intervención del diseño puede reducirse a la réplica con connotaciones de autenticidad. Eso sería indicio de una actitud contemplativa y nostálgica sin posibilidades, más allá de la evocación.

En el recorte específico desde el diseño, proponemos hurgar en los significados del pasado para desarrollar una representación acorde con el presente.

Pasado y presente deben sintetizarse en una dinámica que altere la pasividad concentrada en uno u otro extremo. 
Se ha intentado muchas veces preservar el patrimonio de toda contaminación extraña. Ese camino de reserva cultural es un punto de partida válido, pero no operativo para el diseño. Si no somos capaces de generar nuevas propuestas, no llegaríamos a transformar el modelo sino a complementarlo con expresiones folklóricas que el mismo modelo puede absorber.

La meta que planteamos está en la producción de imágenes nuevas, en la mención evocativa e identificable para la memoria colectiva.

Hauser dice con respecto a este tema: "Lo que del pasado llega a ser actual no depende de la clase de fenómenos, sino del presente respectivo".

Su comentario se centra en el arte y se refiere a formas estilísticas que surgen como evocación de significados que parecían perdidos.

También interesa recordar la producción literaria de los últimos tiempos en América Latina: los significados permanecen como fuente inagotable y resurgen en la metáfora con una sintaxis nueva.

\section{Ética y estética}

Ciertamente lo que pretendemos es el consenso sobre una estética propia, partiendo de principios éticos de identidad. El diseño es expresión cultural a través de formas y como tal podría considerarse un lenguaje. Busquemos entonces "expresiones con sentido" para ese lenguaje y allí estará la valoración estética.

Si analizáramos en la historia del diseño los procesos de cambio, detectaríamos evoluciones y revoluciones en la estética. Las evoluciones son cambios estilísticos que no ponen en crisis los significados de las formas. Las revoluciones son rupturistas y producen cambios cualitativos en la significación. 
Así proponemos una utopía para la transformación: los significados del diseño no serán intrínsecos al modelo, sino a la cultura original.

El diseño es una relación constante entre operatoria y significación. La operatoria como método e instrumentos (tanto teórico como materiales) y la significación como objetivo para ese proceso.

Tal vez lo más difícil de precisar son los límites en el potencial creativo del diseñador. El peligro está en el encasillamiento que bloquea las posibilidades de innovación o en el deslumbramiento que incentiva hacia otras imágenes. Esta advertencia sería de perogrullo si el diseñador asumiera el compromiso ético desde su formación, abordando ya los modos operativos para el planteo estético.

Otra utopía para la transformación: una valoración estética que contradice la ética del modelo.

\section{La tipología en la significación de las formas}

El concepto de tipología implica una clasificación de las formas según rasgos de constancia. Así se definen los "tipos" o estructuras formales característicos de una cultura.

En la operatoria del diseño hay instancias de decisión que corresponden a ideas o concepciones más generales, que trascienden la problemática específica de un objeto. Esas instancias suelen ser ignoradas en el proceso y son necesariamente recurrentes a la memoria o a la razón. La memoria está a menudo interferida por imágenes distorsionantes. La razón puede elegir y deslindar acudiendo a la tipología, como portadora de significados.

Los rasgos tipológicos aseguran la pertenencia de las formas a la cultura que las justifica. El diseño relaciona también constantes y variables: las unas como permanencia de los tipos y las otras como desarrollo de nuevas alternativas para los objetos, en su funcionalidad y tecnologías específicas. 


\section{La tecnología en la producción de las formas}

La relación aparentemente simbiótica entre forma, función y producción es tema polémico en el campo del diseño. El lema de "la forma sigue a la función" fue vigente durante buena parte de este siglo, según la concepción racionalista de las escuelas de Diseño y Arquitectura. Más tarde otras corrientes de pensamiento produjeron un cambio conceptual. La relación se hizo superadora de jerarquías.

Para nosotros, la interacción entre forma, función y producción es límite y potencial a la vez. Si fuera aceptada como ecuación de una sola variable, sería una limitación paralizante para el diseñador. Es necesario sin embargo, que las premisas tecnológicas y aún las alternativas, no se aparten del referente productivo del contexto.

Así vuelve a aparecer en la polémica nuestra condición de periferia en relación a tecnologías más avanzadas. Si aludiéramos a la vieja antinomia entre producción industrial y producción artesanal, estaríamos otra vez en la encrucijada de la dependencia. Son modos productivos diferentes en contextos diferentes.

La artesanía y pequeña o mediana industria constituyen el referente tecnológico del medio. El diseño encontrará el camino de sus posibilidades desde y hacia la producción. La tecnología sugiere, condiciona y a la vez puede responder a los planteos del diseño, hasta encontrar el verdadero potencial de los recursos.

Es indudable que las consecuencias que buscamos en esta orientación, dependen de la convicción en los objetivos. El diseño puede ser un factor de cambio si se integra adecuadamente a la tecnología, incentivándola en un proceso de ida y vuelta. Guy Bonsiepe, un analista del diseño en América Latina, dice que "el criterio clave para la práctica, enseñanza e investigación del diseño consiste en el aporte a la liberación tecnológica y cultural". Lo importante es investigar posibilidades para el potencial propio. 


\section{Una tendencia significativa}

Tal vez lo que estamos proponiendo se traduzca en criterios de ensimismamiento para una sociedad alterada, extrapolando términos de Ortega y Gasset.

El punto de partida deberá ser obviamente, una profunda autoestima y valoración de lo propio. Los alegatos discursivos y concientizadores llegan muchas veces a movilizar la identidad latente en la sociedad. Pero las imágenes de nuestro hábitat cotidiano deberían ser la constante presencia de esa identidad.

Si los aportes del diseño se manifestaran sólo en objetos reminiscentes aislados, no tendrían vigencia como signos de un modelo alternativo. Si las pautas de contraste no se producen claramente, terminaríamos por reafirmar el modelo que rechazamos.

La consigna válida para nuestros objetivos es generar una tendencia significativa en el diseño. La acción conjunta y recurrente de los diseñadores, sin concesiones distorsionantes, deberá ser incentivada desde las Escuelas de Diseño. Desde ya el proceso enseñanza-aprendizaje no puede ser neutro ideológicamente, sino comprometido y coherente en la propuesta académica.

La claridad en los objetivos definirá la validez de los instrumentos teóricos.

\section{Diseño y no dependencia}

Lo que hemos propuesto en estas páginas podríamos sintetizarlo en ese juego de palabras entre comienzo y final de la ponencia. Diseño y dependencia o diseño y no dependencia son opciones que comprometen profundamente al diseñador. Su práctica se traduce en un hecho comunicado mal, con todas las implicancias de esa magnitud.

Es indudable que los incentivos profesionales podrían ser mayores, si la política global estimulara los cambios de orientación. Sin embargo, la opción sigue siendo ineludible y el diseño puede elegir la meta del consenso social sobre un modelo alternativo. 
El arquitecto Andrea Branzi dice en un reportaje: "La identidad latina existe sólo como intuición, no como método. Enseña la potencia secreta del pensamiento y la cultura, produce significados extraños, esconde la ironía de los mecanismos lógicos y dice que la tecnología sirve al diseño y no a la inversa. Esta puede producir hoy, grandes y nuevos proyectos. Es su debilidad la que proporciona una nueva fuerza". Coincidimos con Branzi en la calibración de nuestras posibilidades. Esos grandes y nuevos proyectos que augura son logrables, si los abordamos con convicción desde las capacidades propias en tecnología y diseño.

Buscamos una nueva conciencia sobre la realidad, desde nuestras raíces, hacia nuestra sensibilidad y a través de nuestro potencial. El desafío es grande y la ética que nos sustenta es el impulso, para una nueva ponderación de nuestras fuerzas.

\section{Referencias Bibliográficas}

"EL DISEÑO DE LA PERIFERIA" / Guy Bonsiepe

"LOS CRÍMENES DE LA PAZ" / F. Basaglia y F. B. Ongaro

"LOS LABERINTOS DE LA CRISIS" / Alcira Argumedo

"MORFOLOGÍA" / R. Doberti

"LA IDEA DE TIPO EN ARQUITECTURA" / Bonifacio - Giordano Fleider 
